\title{
Rheumatoid arthritis in Kenya. I. Clinical observations
}

\author{
L. R. BAGG ${ }^{1}$ D. P. HANSEN, ${ }^{1}$ C. LEWIS, ${ }^{1}$ AND V. HOUBA ${ }^{2}$
}

From the ${ }^{1}$ Faculty of Medicine, University of Nairobi, Nairobi, Kenya, and the ${ }^{2}$ WHO Immunology Research and Training Centre, Kenyatta National Hospital, Nairobi, Kenya

SUMMARY 76 Kenyan Africans with classical or definite rheumatoid arthritis are described. Their age, sex ratio, and pattern of joint involvement closely resembled that seen in Europe and the USA and differed from that described in West Africa and rural South Africa. However, they showed a marked lack of systemic nonarticular complications, with relatively little functional incapacity. Radiological grading was carried out on 58 cases, and the changes were found to resemble more closely those seen in an English series than in a Nigerian series.

In the past it has been said that rheumatoid arthritis (RA) is uncommon in tropical Africa. Gelfand (1957) rarely saw it in Central Africa, and reports from Malawi (Goodall, 1956), Uganda (Shaper and Shaper, 1958), and Nigeria (Greenwood, 1969) have suggested that it is not an important cause of admission to hospital in these countries. In Kenya a single case of nodular RA seen in Nairobi in 1962 was thought sufficiently unusual to merit a report (Harries, 1962) and in a retrospective analysis of 26000 admissions to the Kenyatta National Hospital in Nairobi, only 5 cases were found (Hall, 1963). A prospective study of patients with polyarthritis, carried out in a Kenyan district hospital in a more rural setting, revealed only 7 further cases of RA over a 2-year period (Hall, 1966).

More recently in a paper from Uganda in which 65 cases of RA were described it was suggested that the condition was commoner in that country than previously believed (Kanyerezi et al. 1970). In view of a clinical impression that cases resembling RA were also being seen at the Kenyatta National Hospital with a greater frequency than would be expected from previous reports it was decided to investigate such cases with the intention of elucidating the clinical pattern of their disease and comparing it with that seen in Europe and elsewhere in Africa.

\section{Patients and methods}

Nairobi lies $80 \mathrm{~km}$ south of the equator at an altitude

Accepted for publication 15 March 1978

Correspondence to Dr L. R. Bagg, The London Hospital, Whitechapel, London E1 1BB. of $5450 \mathrm{ft}(1660 \mathrm{~m})$. The mean annual temperature is $19.4^{\circ} \mathrm{C}$, with a mean maximum of $25 \cdot 2^{\circ} \mathrm{C}$ and a mean minimum of $13.6^{\circ} \mathrm{C}$. The average annual rainfall is $36.7 \mathrm{in}$. $(930 \mathrm{~mm})$ with the rainfall being mainly confined to 2 distinct periods in the year. The Kenyatta National Hospital serves mainly Nairobi and the surrounding heavily populated countryside, but referrals are seen from throughout the 12 million population of Kenya. In 1974 there were 18330 admissions and 563166 outpatient attenders; $88 \%$ of patients seen in medical clinics were of Bantu stock.

Patients attending the outpatient department or admitted to the wards at the Kenyatta National Hospital were seen by referral over an 18-month period. All patients were of African ethnic origin, and the minimum number of investigations requested on each included $x$-rays of hands, feet, and pelvis, haemoglobin, erythrocyte sedimentation rate (ESR) and a slide latex test for rheumatoid factor. In addition serum was saved and later assayed for rheumatoid factor quantitatively by means of a sheep cell agglutination test and latex tests employing human European IgG, human African IgG, and rabbit IgG.

Functional capacity was assessed by the criteria of Duthie et al. (1955), and in 58 patients the severity of the $x$-ray changes was graded according to the criteria of Kellgren et al. (1963).

\section{Results}

In 18 months 76 patients were seen who fulfilled the American Rheumatism Association (ARA) criteria for definite or classical RA (Ropes et al., 1959) 


\section{CLINICAL FINDINGS}

33 patients fulfilled the ARA criteria for classical RA and 43 for definite RA (Table 1). The mean age at presentation was 43 years, and the mean duration of illness was 3.9 years. There were 20 males and 56 females, giving a male : female ratio of $1: 2 \cdot 8$. In the 60 for whom the information is available 16 described the onset as acute and 44 as insidious. In 24 out of the 76 patients typical subcutaneou nodules were present over the elbows, but in none was any other systemic, nonarticular complication of rheumatoid disease found. Clinical examination showed that wrists, knees, fingers, and ankles were all frequently involved (Table 2). The functional capacity of the patients at presentation is detailed in Table 3.

\section{RADIOLOGICAL FINDINGS}

$X$-rays of the hands were available in 69 patients, of the feet in 62 patients, and of the pelvis in 55

Table 1 Clinical data on 76 Kenyan patients with classical or definite $R A$, and 71 Nigerian patients with definite or probable RA described by Greenwood (1969)

\begin{tabular}{lll}
\hline & Kenyan & Nigerian \\
\hline Age at presentation (years) & 43 (mean) & $21-30$ (mode) \\
Mean duration illness (years) & $3 \cdot 9$ & $1 \cdot 7$ \\
Male:female ratio & $1: 2 \cdot 8$ & $1: 0.9$ \\
Subcutaneous nodules & 24 & 1 \\
\hline
\end{tabular}

Table 2 Site of joint involvement assessed clinically in 76 Kenyans with $R A$, at presentation

\begin{tabular}{ll}
\hline Joints & $\%$ with joint involved \\
\hline Wrists & 83 \\
MCPJs 1 & 83 \\
Knees & 78 \\
Ankles & 67 \\
PIPJs ${ }^{2}$ & 65 \\
MTPJs 3 & 50 \\
Elbows & 50 \\
Shoulders & 35 \\
Hips & 18 \\
TIPJs & 2 \\
\hline
\end{tabular}

1Metacarpophalangeal joints. 2Proximal interphalangeal joints. 3 Metatarsophalangeal joints. 4 Terminal interphalangeal joints.

Table 3 Disability at presentation (based on the criteria of Duthie et al., 1955) of 76 Kenyans, 71 Nigerians, and 307 Scots with RA (figures as percentages)

\begin{tabular}{lccc}
\hline $\begin{array}{l}\text { Grade of } \\
\text { disability }\end{array}$ & Kenyans & Nigerians $^{1}$ & Scots $^{2}$ \\
\hline 1 & 0 & 6 & 0 \\
2 & 64 & 28 & 35 \\
3 & 32 & 44 & 43 \\
4 & 4 & 22 & 23 \\
Total & 100 & 100 & 100 \\
\hline
\end{tabular}

'Data of Greenwood (1969). 2Data of Duthie et al. (1955). patients. Erosive changes were present in 51 cases, with the carpus being most commonly and severely $\overrightarrow{\vec{F}}$ involved. Changes of sacroiliitis were not seen. The severity of the $x$-ray changes in those patients in whom the films were graded is shown in Table 4.

\section{Discussion}

In terms of age, sex, pattern of joint involvement, $\vec{\circ}$ and nodularity the patients more closely resemble their European counterparts than those patients $\vec{\omega}$ described in West Africa (Greenwood, 1969) and rural South Africa (Beighton et al., 1975), where a male preponderance has been reported and rheu- $\infty$ matoid nodules would appear to be uncommon. There was, however, a striking absence of the sys- $\tilde{\omega}$ temic nonarticular complications of rheumatoido disease, and few patients showed the more severe degrees of disability at presentation. The mildness T of the disease in Africans has been commented upon 0 previously (Greenwood, 1969). The reason for this is obscure, though multiple parasitic infections have been suggested to exert a modifying influence $\vec{\theta}$ (Greenwood, 1968), and there is evidence from 0 animal experiments that malaria may supress the development of autoimmune disease (Greenwood et al., 1970). Any comparison between the figures for functional capacity in our patients and the Scottish and Nigerian patients, shown in Table 3 , should be $\frac{\circ}{\Phi}$ modified by the fact that all the Scots and $70 \%$ of the Nigerians were inpatients, whereas only $20 \%$ of the Kenyans were inpatients. Furthermore, criteria such as ability to perform everyday activities, with or without assistance or recourse to mechanical aids, do not necessarily select patients with the same degree of disability in different cultures.

The severity of the radiological changes seen in the Kenyan patients more closely resembles that seen in $\delta$ an English study (Thould and Simon, 1966) than $₹$ that reported in Nigerians. In particular the absent 9 or minimal changes so prominent in the Nigerian patients were not frequently seen in our patients.

The opinion is often heard that many of the conditions stated by physicians working in Africa $O$

Table 4 Radiological findings in 58 Kenyan, 69 Nigerian, and 105 English patients with RA graded according to the criteria of Kellgren et al. (1963) (figures as percentages)

\begin{tabular}{|c|c|c|c|}
\hline Grade & Kenyan & Nigerian 1 & English ${ }^{2}$ \\
\hline $\begin{array}{c}0-1 \\
2 \\
3 \\
4 \\
\text { Total }\end{array}$ & $\begin{array}{r}19 \\
38 \\
36 \\
7 \\
100\end{array}$ & $\begin{array}{r}69 \\
21 \\
8 \\
2 \\
100\end{array}$ & $\begin{array}{r}17 \\
36 \\
32 \\
15 \\
100\end{array}$ \\
\hline
\end{tabular}

1Data of Greenwood (1969). ${ }^{2}$ Data of Thould and Simon (1966). 
in earlier years to be rare in Africans were in fact always present. The postulate is that they were not specifically sought out and passed unnoticed amidst the large number of cases of more obtrusive, lifethreatening diseases. In the early 1960s, however, Hall specifically investigated the problem of arthritis in Kenya, and from his figures it can be inferred that RA was seen infrequently in Kenyan Africans attending hospital at that time (Hall, 1963, 1966). The figures from this study suggest that the disease is now being seen much more frequently in patients attending hospital. A similar experience has recently been reported from Uganda (Kanyerezi et al., 1970).

Hospital data are an unreliable guide to the prevalence of a disease in a community, and our experience may simply reflect a greater ease of access to medical facilities in Kenya in recent years rather than a true increase in incidence of RA in the population. However, surveys of rural and urban African communities in South Africa have shown a higher prevalence of RA in the urban population (Beighton et al., 1975; Solomon et al., 1975), and it is notable that a marked trend towards urbanisation is a prominent feature of modern Kenyan society. There is now a pressing need for similar community surveys in Kenya, since if the prevalence should prove to be rising, as the hospital data suggests, then an epidemiological approach to the problem could reveal important information about the aetiology of the disease.

We thank Professor M. A. Floyer for his helpful advice, and the many physicians at the Kenyatta National Hospital who refered their patients to us for study.

\section{References}

Beighton, P., Solomon, L., and Valkenburg, H. A. (1975). Rheumatoid arthritis in a rural South African Negro population. Annals of the Rheumatic Diseases, 34, 136-141.
Duthie J. J. R. Thompson, M,. Weir, M. M., and Fletcher. W. B. (1955). Medical and social aspects of the treatment of rheumatoid arthritis. Annals of the Rheumatic Diseases, 14, 133-149.

Gelfand, M. (1957). The Sick African, 3rd edn. Juta: Cape Town.

Goodall, J. W. D. (1956). Joint swellings in Africans. Central African Journal of Medicine, 2, 220-223.

Greenwood, B. M. (1968). Autoimmune disease and parasitic infections in Nigerians. Lancet, 2, 380-382.

Greenwood, B. M. (1969). Polyarthritis in Western Nigeria. I. Rheumatoid arthritis. Annals of the Rheumatic Diseases, 28, 488-496.

Greenwood, B. M., Herrick, E. M., and Voller, A. (1970). Supression of autoimmune disease in NZB and (NZB/ $\mathrm{NZW}) \mathrm{F} 1$ hybrid mice by infection with malaria. Nature, 226, 266-267.

Hall, L. (1963). Polyarthritis in Nairobi Africans. East African Medical Journal, 40, 354-358.

Hall, L. (1966). Polyarthritis in Kenya. East African Medical Journal, 43, 161-170.

Harries, J. R. (1962). Rheumatoid nodules in an African. East African Medical Journal, 39, 69-70.

Kanyerezi, B. R., Baddely, H., and Kisumba, D. (1970). Rheumatoid arthritis in Ugandan Africans. Annals of the Rheumatic Diseases, 29, 617-621.

Kellgren, J. H., Jeffrey, M. R., and Ball, J. (1963). The Epidemiology of Chronic Rheumatism, Vol. 2. Blackwell: Oxford.

Ropes, M. W., Bennett, G. A., Cobb, S., Jacox, R., and Jessar, R. A. (1959). 1958 revision of diagnostic criteria for rheumatoid arthritis. Annals of the Rheumatic Diseases, 18, 49-53.

Shaper, A. G., and Shaper, L. (1958). Analysis of medical admissions to Mulago hospital, 1957. East African Medical Journal, 25, 647-678.

Solomon, L., Robin, G., and Valkenburg, H. A. (1975). Rheumatoid arthritis in an urban South African Negro population. Annals of the Rheumatic Diseases, 34, 128135.

Thould, A. K., and Simon, G. (1966). Assessment of radiological changes in the hands and feet in rheumatoid arthritis. Annals of the Rheumatic Diseases, 25, 220-228. 